\title{
ИССЛЕДОВАНИЕ ЗЕРНА И МУКИ СЕЛЕКЦИОННЫХ СОРТОВ ПРОСА ДЛЯ СОЗДАНИЯ МУЧНЫХ КОНДИТЕРСКИХ И КУЛИНАРНЫХ ИЗДЕЛИЙ СПЕЦИАЛИЗИРОВАНОГО НАЗНАЧЕНИЯ
}

\author{
Т.С. Баженова, И.А. Баженова, Э.Э. Сафонова
}

При производстве продуктов специализированного назначения особое внимание уделяется зерновым и зернобобовым культурам. Для продовольственной безопасности РФ актуально возрождение русских культур. Одной из них является просо, которое содержит основные макронутриенты, клетчатку, витамины, минеральные элементы. Отсутствие в белках проса глютена позволяет использовать его при производстве продуктов для людей, страдающих целиакией. На потребительском рынке таких продуктов нет. Поэтому актуально создание линейки продукции на основе зерна проса и продуктов его переработки. В данной работе были исследованы фризико-химические показатели зерна и муки проса, определен состав жирных кислот зерна, содержание каротиноидов, общее количество френольных соединений. Разработаны рецептуры песочного печенья с частичной и полной заменой пшеничной муки на пшенную, песочного печенья с добавлением тыквы, блинного теста с частичной и полной заменой пшеничной муки на пшенную, пирогов с добавлением моркови с комбинированием пшеничной, пшенной, амарантовой и льняной муки. Уделено особое внимание оптимизации классической рецептуры блинного теста для производства изделий с частичной и полной заменой пшеничной муки на пшенную. Проведена дегустационная оценка всех опытных образцов. Даны рекомендации по использованию разработанных мучных кондитерских и кулинарных изделий в специализированном питании.

Ключевые слова: просо, специализированные продукты, пшенная мука, льняная мука, амарантовая мука, комбинирование разных видов муки, глютен, целиакия, блинное тесто, рецептуры, мучные кондитерские и кулинарные изделия, пищевая ценность, дегустационная оценка.

В настоящее время во всем мире быстрыми темпами развивается рынок специализированных продуктов. Это связано с тем, что становится больше групп людей, нуждающихся в особых рационах. Согласно ТP ТС 021/2011 «О безопасности пищевой продукции» специализированная пищевая продукция - пищевая продукция, для которой установлены требования к содержанию и (или) соотношению отдельных веществ или всех веществ и компонентов и (или) изменено содержание и (или) соотношение отдельных веществ относительно естественного их содержания в такой пищевой продукции и (или) в состав включены не присутствующие изначально вещества или компоненты (кроме пищевых добавок и ароматизаторов) и (или) изготовитель заявляет об их лечебных и (или) профилактических свойствах, и которая предназначена для целей безопасного употребления этой пищевой продукции отдельными категориями людей [1]. Специализированные продукты создаются для:
- спортсменов с целью обогащения рациона основными макро- и микронутриентами и оптимизации рациона в тренировочный и соревновательный периоды;

- беременных и кормящих женщин с целью восстановления баланса основных веществ и элементов в организме;

- пожилых людей с целью продления активной жизни и поддержания основных фризиологических функций организма;

- детей разного возраста, учитывающие особенности растущего организма;

- людей, работающих в экстремальных условиях или проживающих в неблагоприятной экологической обстановке.

Кроме того, продукты, создаваемые как диетические, также могут быть отнесены к разряду специализированных.

Одним из заболеваний, требующих пожизненной диеты, является целиакия (глютеновая энтеропатия). Перспективным направлением создания безглютеновых продуктов является, например, применение добавок из муки расторопши, лебеды или амаранта [2]. 


\section{ИССЛЕДОВАНИЕ ЗЕРНА И МУКИ СЕЛЕКЦИОННЫХ СОРТОВ ПРОСА ДЛЯ СОЗДАНИЯ МУЧНЫХ КОНДИТЕРСКИХ И КУЛИНАРНЫХ ИЗДЕЛИЙ СПЕЦИАЛИЗИРОВАННОГО НАЗНАЧЕНИЯ}

Поэтому обеспечение продуктами питания людей, страдающих целиакией, - актуальная социальная проблема во многих странах миpa [3].

Для создания специализированных и диетических продуктов используются различные традиционные и альтернативные зерновые, зернобобовые и псевдозерновые культуры. В настоящее время в производство продуктов широко внедряют амарант и продукты его переработки, люпин, лён, полбу и др. Эти культуры используют для производства мучных, макаронных изделий, зерновых смесей, талканов [4]. При этом ассортимент мучных кондитерских изделий недостаточен.

В разработанной Правительством РФ «Стратегии развития пищевой и перерабатывающей промышленности на период до 2020 года» подчеркнута необходимость внедрения технологий, позволяющих расширить производство лечебно-профилактических, геронтологических и других продуктов специализированного назначения [5].

В современных условиях экономических санкций и импортозамещения актуальным является возрождение культур, которые издавна возделывались в России - просо, овес, полба, шаровидные пшеницы и т.д. Использование данных культур недостаточно при производстве продуктов специализированного и диетического питания.

Цель данной работы - изучение возможности использования проса и пшенной муки в традиционных рецептурах, а также разработка технологий изготовления мучных кондитерских и кулинарных изделий специализированного назначения.

Объектом исследования было выбрано зерно проса посевного Panicum miliaceum L. сортов российской селекции Альба, Спутник, Регент, Казачье. Они характеризуются высокой урожайностью, устойчивостью к заболеваниям и полеганию, хорошими товароведными показателями качества зерна, высоким выходом крупы [6, 7].

В работе были исследованы состав жирных кислот зерна, содержание каротиноидов, общее количество фенольных соединений, кислотность муки.

При анализе состава жирных кислот для всех сортов отмечено наибольшее содержание кислот 18:2w6,9c - около $67 \%$; 18:1n9 около 21\%; 16:0 - около 9\%. Также выявлены сортовые различия в содержании стеариновой кислоты и минорных жирных кислот [6].

Окраска зерна коррелирует с содержанием каротиноидов. Наибольшее содержание каротиноидов выявлено у сорта Спутник $1,15 \pm 0,11$ мг/100 г, наименьшее - у сорта Альба, зерна которого имеют самую светлую

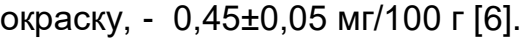

При разработке рецептур мучных кондитерских изделий была проведена частичная или полная замена пшеничной муки на пшенную, а также комбинирование пшенной, льняной и амарантовой муки. Был проведен сравнительный анализ компонентного состава данных видов муки, представленный в таблице 1.

Таблица 1 - Компонентный состав пшеничной, льняной, амарантовой и пшенной муки.

\begin{tabular}{|l|c|c|c|c|}
\hline Вид муки & Белки, г & Жиры, г & Углеводы, г & $\begin{array}{l}\text { Энергетическая } \\
\text { ценность, ккал }\end{array}$ \\
\hline Пшеничная, вс & 10,0 & 1,0 & 71,0 & 330 \\
\hline Льняная & 25,0 & 5,0 & 40,0 & 300 \\
\hline Амарантовая & 9,5 & 3,9 & 67,8 & 344 \\
\hline Пшенная & 11,5 & 3,5 & 58,0 & 330 \\
\hline
\end{tabular}

Замена пшеничной муки на альтернативные виды позволяет улучшить пищевую ценность изделий, повысить содержание пищевых волокон, каротиноидов, незаменимых жирных кислот, минеральных элементов и биофлавоноидов. Все опытные образцы прошли дегустационную оценку и анализ физико-химических показателей (влажность, зольность, кислотность теста, щелочность печенья) [6]. Традиционные рецептуры были изменены и применялись только в качестве контрольного образца. В опытных образцах применяли следующие соотношения: 50\% пшенной муки и 50\% пшеничной, 50\% цельносмолотой пшенной муки и 50\% пшеничной, $50 \%$ пшенной и 50\% амарантовой, комбинирование трех видов муки - пшенной, амарантовой и льняной в равных соотношениях.

Пшенная мука является источником лейцина (высокое содержание которого связано с проламинами), фосфора, магния, кремния, цинка, меди, брома. Мука из цельносмолотого зерна проса позволяет получить готовые изделия, богатые балластными веществами (целлюлозой гемицеллюлозой, лигнином). Пищевые волокна нормализуют 
липидный, водно-солевой обмен, способствуют выведению из организма токсичных веществ, стимулируют перистальтику кишечника. Калорийность изделий из такой муки снижается, что отвечает рекомендациям диетологов. Однако замена пшеничной муки на альтернативные виды муки значительно ухудшает реологические свойства теста, а также качество готового продукта.

Это происходит потому,

что белки муки не могут сформировать клейк овину хорошего качества.

Амарантовая мука служит источником кальция, магния, фосфора, витаминов С и PP. Изделия с применением амарантовой муки приобретают золотистый цвет и ореховый привкус.

Льняная мука нормализует работу желудочно-кишечного тракта благодаря высокому содержанию пищевых волокон и клейких веществ (льняной слизи). Кроме того, льняная мука богата антиоксидантами, лигнанами, тормозящими развитие онкологических заболеваний. По составу белка и набору жирных кислот льняная мука превосходит муку многих других культур. Льняная мука обладает хорошими влагопоглощающими свойствами, поэтому выпечка долго не черствеет.

Перспективными направлениями использования зерна проса можно считать применение его для приготовления видов теста, не требующих высокого качества клейковины, а также комбинирование крупы и муки из про- са с мукой из других видов зерновых культур. Это позволит создавать широкий ассортимент блюд и продуктов специализированного назначения.

Были разработаны рецептуры песочного печенья с частичной и полной заменой пшеничной муки на пшенную, песочного печенья с добавлением тыквы, блинного теста с частичной и полной заменой пшеничной муки на пшенную, пирогов с добавлением моркови в рецептуру теста. Проведена дегустационная оценка всех опытных образцов.

Особое внимание было уделено блинному тесту, так как изделия из этого вида теста, являясь традиционно русскими, известными со времен Древней Руси, и в настоящее время не утратили популярность [8]. С возросшим в последнее время интересом к русской кухне увеличивается и количество предприятий общественного питания, реализующих изделия из блинного теста не только во время Масленичной недели, но и в повседневном меню. Сохраняя традиции, следует исследовать и оптимизировать состав блюд в соответствии с актуальными требованиями потребителей. Так, блинное тесто, обладая высокими органолептическими характеристиками, не содержит всех необходимых ингредиентов, преобладающими веществами являются углеводы. Для повышения качества изделий из блинного теста зачастую используют овощи, фрукты и продукты их переработки.

Таблица 2 - Рецептуры образцов блинного теста

\begin{tabular}{|c|c|c|c|c|c|}
\hline $\begin{array}{c}\text { Наименование } \\
\text { сырья }\end{array}$ & $\begin{array}{c}\text { Образец №1 } \\
\text { пшеничная } \\
\text { мука 100\% } \\
\text { (контроль) }\end{array}$ & $\begin{array}{c}\text { Образец №2 } \\
\text { пшеничная: } \\
\text { пшенная мука, } \\
70: 30\end{array}$ & $\begin{array}{c}\text { Образец №3 } \\
\text { пшеничная: } \\
\text { пшенная мука, } \\
\text { 50:50 }\end{array}$ & $\begin{array}{c}\text { Образец №4 } \\
\text { пшеничная: } \\
\text { пшенная мука, } \\
30: 70 \\
\end{array}$ & $\begin{array}{c}\text { Образец №5 } \\
\text { пшенная мука, } \\
100 \%\end{array}$ \\
\hline & \multicolumn{5}{|c|}{ Масса сырья, г } \\
\hline 1 & 2 & 3 & 4 & 5 & 6 \\
\hline Мука пшеничная & 83 & 58 & 42 & 25 & - \\
\hline Мука пшенная & - & 25 & 42 & 58 & 83 \\
\hline Вода & 208 & 208 & 208 & 208 & 208 \\
\hline Яйцо & 17 & 17 & 17 & 17 & 17 \\
\hline Cахар-песок & 5 & 5 & 5 & 5 & 5 \\
\hline Соль & 1,5 & 1,5 & 1,5 & 1,5 & 1,5 \\
\hline $\begin{array}{l}\text { Растительное } \\
\text { масло }\end{array}$ & 3 & 3 & 3 & 3 & 3 \\
\hline Выход & 200 & 200 & 200 & 200 & 200 \\
\hline $\begin{array}{l}\text { Энергетическая } \\
\text { ценность }\end{array}$ & 343,8 & 345,3 & 350,0 & 347,9 & 349,6 \\
\hline
\end{tabular}

В данном исследовании было обращено внимание на основной ингредиент - муку, из которой производят тесто. При проработке технологии приготовления блинного теста производили замену пшеничной муки на пшенную в процентном соотношении 70:30,
50:50, 30:70 и полную замену пшеничной муки на пшенную. Рецептуры приведены в таблице 2 [9]. Также для каждого образца была определена энергетическая ценность. Из таблицы 2 видно, что все опытные образцы 


\section{ИССЛЕДОВАНИЕ ЗЕРНА И МУКИ СЕЛЕКЦИОННЫХ СОРТОВ ПРОСА ДЛЯ СОЗДАНИЯ МУЧНЫХ КОНДИТЕРСКИХ И КУЛИНАРНЫХ ИЗДЕЛИЙ СПЕЦИАЛИЗИРОВАННОГО НАЗНАЧЕНИЯ}

имеют примерно одинаковую энергетическую ценность.

При замесе теста было установлено, что содержание клейковины в пшенной муке меньше, чем в пшеничной. Кроме того, клейковина пшенной муки вбирает мало жидкости, в результате чего тесто получается более жидким, и вода отслаивается. Из-за оседания пшенной муки тесто получается неравномерное, поэтому была отмечена необходимость просеивать пшенную муку с помощью очень мелкого сита. Данные расчетов представлены в диаграмме на рисунке 1.

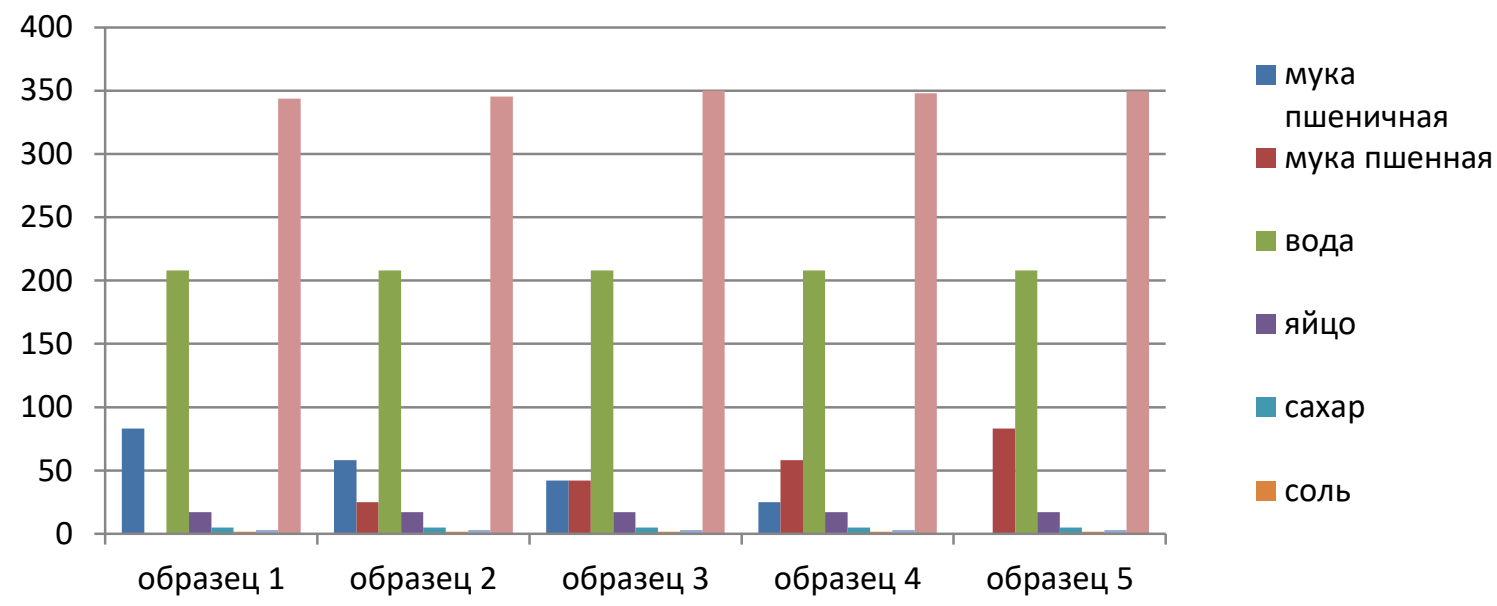

Рисунок 1 - Данные расчетов экспериментальных рецептур

Качество готовых изделий определялось количеством введенной пшенной муки. С увеличением этого количества готовые блины имели более выраженный желтый цвет, но хуже удерживали фрорму и приобретали крошащуюся текстуру. При увеличении содержания пшенной муки более 50\% готовые изделия приобретали ореховый привкус.

Наиболее высокие оценки получил образец №2, представленный на рисунке 1. Более высокое содержание пшенной муки приводило к ухудшению реологических свойств теста, внешнего вида готовых изделий и консистенции. Образцы №4 и 5 практически невозможно было перевернуть, они не отставали от сковороды, рвались. Также была отмечена излишняя влажность и не пропеченность готовых блинов [10].

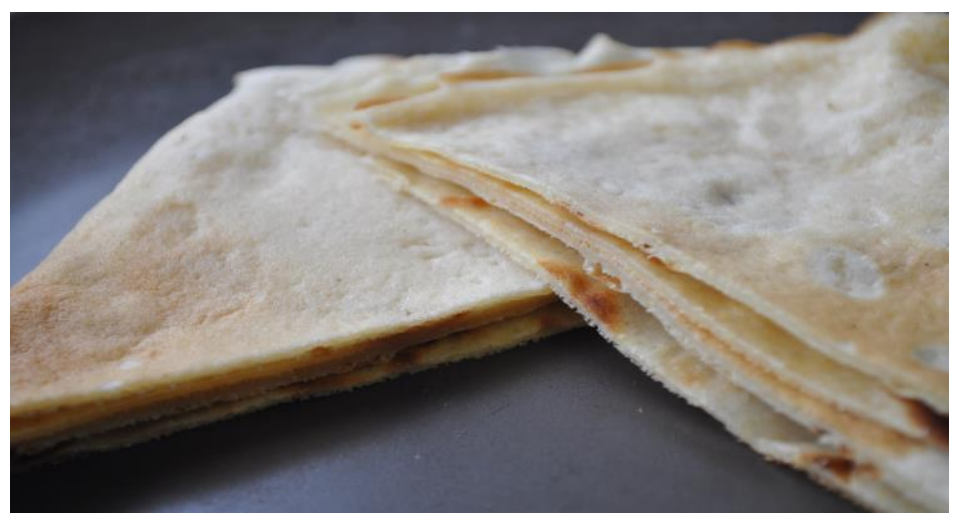

Рисунок 2 - Образец №2

Также были разработаны рецептуры морковных кексов с комбинированием пшеничной, пшенной, амарантовой и льняной муки. В опытных образцах применялись следующие соотношения: $50 \%$ пшенной муки и
$50 \%$ пшеничной, 50\% цельносмолотой пшенной муки и 50\% пшеничной, 50\% пшенной и $50 \%$ амарантовой, комбинирование трех видов муки - пшенной, амарантовой и льняной - в равных соотношениях [9]. 
Образцы морковных кексов получили разные оценки дегустаторов. Вкусовые качества были оценены достаточно высоко, а консистенция и структура изделий вызвала противоречивые отзывы: были отмечены излишняя влажность и вязкость изделий.

Наилучшие результаты были получены при отработке рецептур песочного печенья с комбинацией различных видов муки - пшенной, амарантовой и льняной. Наивысшие оценки получили образцы №1 (пшеничная: пшенная мука, 50:50) и №2 (пшенная: амарантовая мука, 50:50). Для них была отмечена высокая пористость и рассыпчатость изделий. Образцы №3 (пшенная: льняная мука, 50:50) и 4 (пшенная: амарантовая: льняная мука, 33:33:33), при изготовлении которых добавляли льняную муку, имели серокоричневый цвет, непривычный для потребителей привкус льняного семени. Они получили самые низкие оценки дегустаторов. У образца №5 (замена пшеничной муки на пшенную муку, 100\%), отмечены хорошие вкусовые качества, но плохая сохраняемость фрормы [10].

Проведенные исследования доказали, что продукты переработки проса могут использоваться для создания мучных кулинарных и кондитерских изделий специализированного назначения. Выявленные недостатки могут быть устранены при соответствующей доработке рецептур и технологии. Предложенные мучные смеси могут быть использованы для производства продуктов из теста, не требующего хорошего качества клейковины (песочного, затяжного, бисквитного, блинного). А введение в рецептуры овощных, фрруктовых и ягодных пюре позволит обогатить их витаминами и другими биологически активными веществами [6].

Таким образом, использование зерна проса является перспективным для расширения ассортимента мучных кондитерских изделий специализированного назначения, а также для производства безглютеновых продуктов.

\section{СПИСОК ЛИТЕРАТУРЫ}

1. Технический регламент Таможенного союза ТP ТС 021/2011 «О безопасности пищевой продукции» от 9 декабря 2011 г. № 880.

2.Москвичева Е.В., Сафонова Э.Э., Тимошенкова И.А. Использование муки из семян расторопши в производстве безглютеновой продукции.Международный научно-исследовательский журнал № 8, ч. 3 / 2017.

3. Актуальность проблемы продовольствия сегодня. // Журнал «Актуальные проблемы науки и практики» №1 (001). Декабрь 2015 г. - стр. 36-40.
4. Баженова И.А. Исследование технологических свойств зерна полбы. (TRITICUM DICOCCUM SCHRANK.) и разработка кулинарной продукции с его использованием: дисс. ...канд. техн. наук / Санкт-Петербургский торгово-экономический институт. Санкт-Петербург, 2004

5. Янова М.А., Колесникова Н.А., Мучкина Е.Я. Исследование проса и продуктов его переработки. - Журнал Вестник Красноярского государственного аграрного университета. Выпуск № $11 /$ 2015.

6. Tatiana Bazhenova, Irina Bazhenova. Use of millet flour for production of special purpose goods// $11^{\text {th }}$ International Scientific Conference «Students on their way to science» (undergraduate, graduate, postgraduate students) - Latvia - 2016

7. Справка о научно-практическом применении результатов научной деятельности по просу посевному (Panicum miliaceum L.). - Орел, ФГБНУ «Всероссийский научно-исследовательский институт зернобобовых и крупяных культур», 2014.

8. Варлахова Л.Н., Варлахов М. Д., Агаркова С.Н., Головина Е.В., Иванова Т.Н. Старинные и новые блюда из зернобобовых и крупяных культур. - Орел, ВНИИЗБК, 2001. - 282 с.

9. Т.С. Баженова, Н.В. Барсукова, И.А. Баженова. Технологические аспекты применения селекционных сортов проса для создания специализированных продуктов. // XV Международная конференция молодых ученых «Пищевые технологии и биотехнологии» (г. Казань, 13-14 апреля 2016 г.). Сборник материалов конференции. - Казань: Издательство «БРИГ», 2016. - 476 с.

10. Баженова Т.С., Баженова И.А. Разработка рецептур мучных кулинарных и кондитерских изделий с использованием пшенной муки для специализированного питания. Инновации в технологии продуктов здорового питания: международная научная конференция: материалы. - Калининград, Издательство ФГБОУ ВО «Калининградский государственный технический университет», 2016. С. 40-47

Баженова Татьяна Сергеевна, старший преподаватель Высшей школы биотехнологии и пищевых технологий СанктПетербургского политехнического универcumema, тел. 8-950-022-9558, e-mail: tatjanabazhenova@mail.ru

Баженова Ирина Анатольевна, кандидат технических наук, доцент ВШБТиПТ Санкт-Петербургского политехнического университета, тел. 8-921-375-3058, e-mail: irinabazhenova@mail.ru

Сафонова Эльвира Эмильевна, кандидат педагогических наук, дочент ВШБТиПТ Санкт-Петербургского политехнического университета, тел. 8-981-761-1029, e-mail: elvira-safonova@rambler.ru 